\title{
Pulmonary vascular disease in different types of congenital heart disease Implications for interpretation of lung biopsy findings in early childhood
}

\author{
SHEILA G HAWORTH \\ From the Department of Paediatric Cardiology, Institute of Child Health, London
}

SUMMARY Pulmonary vascular structure was studied by analysing serial reconstructions of the arterial pathways and random sections of tissue in the lungs of 16 children who died with different types of congenital heart disease and pulmonary hypertension. Cases of ventricular septal defect showed an appreciable increase in muscularity of both preacinar and intra-acinar (respiratory unit) arteries, and intimal proliferation was infrequent and mild. By contrast, cases of transposition of the great arteries with ventricular septal defect and atrioventricular septal defect showed an increase in preacinar muscularity, a short heavily muscularised arterial segment containing intimal proliferation at the entrance to the acinus, whereas the intra-acinar arteries beyond showed only a moderate increase in muscularity. In these children who were $<1$ year of age an increase in pulmonary vascular resistance was due to strategically placed small areas of intimal proliferation and not to widespread obliterative pulmonary vascular disease. The study demonstrated and explained differences in the appearance of the peripheral pulmonary arteries in different types of congenital heart disease, which help interpret the findings of lung biopsies.

In an increasing number of children with congenital heart disease and pulmonary hypertension the potential reversibility of pulmonary vascular disease is predicted by examining lung biopsy specimens. In specimens from very young children with early disease the application of quantitative morphometric techniques to assess arterial muscularity and the size and number of respiratory unit arteries is helpful, and the structural changes have been shown to be related to the haemodynamic findings. ${ }^{1}$ At the other end of the spectrum, in older children with advanced disease the classical changes described by Heath and Edwards as grade V and VI pulmonary vascular obstructive disease usually confirm a clinical and haemodynamic assessment of inoperability. ${ }^{2}$ Most biopsy specimens, however, are taken from children who lie between the two extremes and in whom it is difficult to predict

Requests for reprints to Dr S G Haworth, The Hospital for Sick Children, Great Ormond Street, London WCIN 3JH.

Acceptod for publication 28 June 1984 clinically the risk of cardiac surgery and the ultimate reversibility of pulmonary vascular disease.

The structural findings in lung biopsy material from such patients may be difficult to interpret for several reasons. In a lung biopsy specimen only the most peripheral branches of the pulmonary arteries can be examined, and obliterative changes may be absent in such arteries despite an increase in pulmonary vascular resistance. Furthermore, the type and severity of structural damage may vary in the different arteries present in the specimen. It may be difficult to relate the quantitated changes in arterial muscularity, size, and number to the clinical and haemodynamic findings and to relate the quantitated changes to the appearance of the vessels. In addition, in children of similar age who do not have advanced obliterative pulmonary vascular disease the appearance of the vessels may be different in different types of congenital heart disease.

In the present study pulmonary vascular structure was analysed in the necropsy specimens of 16 children who died with different types of congenital heart disease, most of whom had severe pulmonary hyperten- 
Table 1 Clinical data

\begin{tabular}{|c|c|c|c|c|c|c|c|c|c|}
\hline $\begin{array}{l}\text { Case } \\
\text { No }\end{array}$ & Diagnosis & Age at death & Sex & $P A P(R V P)$ & $S A P(L V P)$ & $Q p: Q s$ & $R p: R s$ & $\begin{array}{l}\text { Rpa } \\
\left.\text { (units } m^{2}\right)^{\star}\end{array}$ & $\begin{array}{l}\text { Systemic \% } \\
\text { oxygen sauration }\end{array}$ \\
\hline$\frac{1}{2}$ & $\begin{array}{l}\text { VSD } \\
\text { VSD }\end{array}$ & $\begin{array}{l}9 \mathrm{mth} \\
10 \mathrm{mth}\end{array}$ & $\underset{\mathbf{M}}{\mathbf{F}}$ & $\begin{array}{l}70 / 25 \\
80 / 40\end{array}$ & $\begin{array}{l}85 / 45 \\
85 / 50\end{array}$ & $\begin{array}{l}2.8 \\
1.5\end{array}$ & $\begin{array}{l}0.25 \\
0.43\end{array}$ & 2.7 & $\begin{array}{l}99 \\
98\end{array}$ \\
\hline 3 & VSD & $3.5 \mathrm{yr}$ & $\mathbf{F}$ & $95 / 50$ & $90 / 48$ & 1.4 & 0.57 & $\begin{array}{l}(2 \cdot 0) \\
10.5 \\
(1.4)\end{array}$ & 98 \\
\hline $\begin{array}{l}4 \\
5 \\
6 \\
7\end{array}$ & $\begin{array}{l}\text { TGA, VSD } \\
\text { TGA, VSD } \\
\text { TGA, VSD } \\
\text { TGA, VSD, } \\
\text { LVOTO }\end{array}$ & $\begin{array}{l}2 \mathrm{mth} \\
4 \mathrm{mth} \\
10 \mathrm{mth} \\
11 \mathrm{mth}\end{array}$ & $\begin{array}{l}\mathbf{M} \\
\mathbf{M} \\
\mathbf{F} \\
\mathbf{M}\end{array}$ & $\begin{array}{c}(60 / 0) \\
76 / 25 \\
100 / 63 \\
40 / 15\end{array}$ & $\begin{array}{r}56 / 30 \\
77 / 38 \\
105 / 70 \\
80 / 40\end{array}$ & $\begin{array}{l}\overline{0.4} \\
0.7 \\
1\end{array}$ & $\begin{array}{l}-\overline{2 \cdot 0} \\
1 \cdot 3 \\
0.4\end{array}$ & $\begin{array}{r}14 \cdot 8 \\
21 \cdot 3 \\
3 \cdot 2\end{array}$ & $\begin{array}{l}76 \\
54 \\
51 \\
65\end{array}$ \\
\hline 8 & $\begin{array}{l}\text { TGA, VSD } \\
\text { LVOTO }\end{array}$ & $2 \mathrm{yr}$ & $\mathbf{M}$ & $17 / 6$ & $80 / 45$ & 1.5 & 0.12 & 1.6 & 78 \\
\hline 9 & $\begin{array}{c}\text { TGA, VSD, post } \\
\text { repair SVC } \\
\text { obstruction }\end{array}$ & $4.8 \mathrm{yr}$ & $\mathbf{M}$ & $12 / 6$ & $80 / 45$ & - & - & - & - \\
\hline $\begin{array}{l}10 \\
11 \\
12 \\
13 \\
14 \\
15 \\
16\end{array}$ & $\begin{array}{l}\text { TGA, VSD } \\
\text { AVSD } \\
\text { AVSD, DS } \\
\text { AVSD, DS } \\
\text { AVSD, } \\
\text { Sec ASD } \\
\text { Sec ASD }\end{array}$ & $\begin{array}{l}17 \mathrm{yr} \\
1 \mathrm{~d} \\
5 \mathrm{mth} \\
6 \mathrm{mth} \\
16 \mathrm{yr} \\
5 \mathrm{mth} \\
2 \mathrm{yr}\end{array}$ & $\begin{array}{l}\mathbf{F} \\
\mathbf{F} \\
\mathbf{F} \\
\mathbf{F} \\
\mathbf{F} \\
\mathbf{F} \\
\mathbf{F}\end{array}$ & $\begin{array}{r}84 / 57 \\
65 / 34 \\
\overline{78 / 30} \\
105 / 60 \\
70 / 20 \\
68 / 35\end{array}$ & $\begin{array}{l}82 / 54 \\
(60 / 18) \\
75 / 38 \\
105 / 60 \\
(90 / 0) \\
(86 / 8)\end{array}$ & $\begin{array}{l}\frac{1.4}{7} \\
\frac{1.5}{2} \\
3.3\end{array}$ & $\begin{array}{l}\frac{0.7}{\overline{-}} \\
\frac{0.6}{-} \\
=\end{array}$ & $\begin{array}{l}\frac{13 \cdot 1}{\overline{7}} \\
\overline{17 \cdot 3} \\
\overline{\overline{16}} \\
(8 \cdot 5)\end{array}$ & $\begin{array}{l}71 \\
71 \\
89 \\
\text { C } \\
97 \\
\text { C }\end{array}$ \\
\hline
\end{tabular}

*Figures in brackets denote values after inhalation of $100 \%$ oxygen for 10 minutes.

AVSD, atrioventricular septal defect; DS, Down's syndrome; LVOTO, left ventricular outflow tract obstruction; Sec ASD, secundum atria septal defect; SVC, superior vena caval (obstruction); TGA, transposition of the great arteries; VSD, ventricular septal defect; LVP, left ventricular pressure; SAP, systemic arterial pressure; RVP, right ventricular pressure; $P A P$, pulmonary arterial pressure; $Q p: Q s$, pulmonary to systemic blood flow ratio; Rp:Rs, pulmonary to systemic vascular resistance ratio; Rpa; pulmonary arteriolar resistance; C, cyanosis.

sion. In all 16 cases serial reconstructions of the arterial pathways from the hilum to the capillary bed were made, and the structural changes in the peripheral arteries were related to those in more proximal arteries, vessels which cannot be examined by lung biopsy. In addition, on a large sample of peripheral vessels taken from all parts of the lung arterial muscularity, size, and number were analysed using quantitative morphometric techniques. ${ }^{34}$ These findings have been published previously in four of the cases. ${ }^{56}$ The structural abnormalities in each type of congenital heart disease were compared to see if pulmonary vascular disease develops in a similar manner, but at a different rate, in different types of congenital heart disease.

\section{Material and methods}

\section{DIAGNOSES}

Pulmonary vascular structure was studied in the postmortem lung specimens of 16 patients (six male, 10 female) who died without surgical treatment and who had either an isolated ventricular septal defect, transposition of the great arteries with a ventricular septal defect, an atrioventricular septal defect, or a secundum atrial septal defect with pulmonary hypertension or an increase in pulmonary blood flow or both (Table 1). One additional patient with transposition (case 9) had had an intracardiac repair and died at 4 years 9 months at operation for the relief of superior vena caval obstruction with a normal pressure. Pulmonary vascular resistance was increased in the majority of children in whom it was measured (Table 1). Cardiac catheterisation was performed $1-40$ days before death, except in the patients in cases 8,10 , and 14, who were studied four months, three months, and 10 years before death respectively. Twelve patients died at or soon after palliative or corrective surgery, one (case 11) died soon after admission to hospital, one (case 12) had a purulent meningitis, and two (cases 10 and 14) died with severe pulmonary vascular disease. Extra cardiac malformations included a small persistent ductus arteriosus (cases 4, 5, and 14), the lumen measuring $1 \mathrm{~mm}$ in diameter in the patient in case 14. One patient (case 11) aged 1 day had coarctation of the aorta and a persistent ductus arteriosus.

\section{PATHOLOGICAL TECHNIQUES}

The pulmonary arteries of one lung were injectd with a barium-sulphate gelatin mixture in 11 cases. Injected and uninjected tissue was studied in an identical $N$ manner. The posterobasal arterial pathway of the $N$ right lower lobe and its lateral branches was reconstructed in 12 cases, the corresponding pathway of the left lung was reconstructed in three (cases 6,10 , and 12), and the posterior pathway of the right upper lobe in one (case 1). In each case the relevant lobe of lung was sliced at $0.5 \mathrm{~cm}$ intervals. Either the entire slice or, in the large specimens, $1 \mathrm{~cm}^{2}$ of tissue containing the main artery was embedded in paraffin, $4 \mu \mathrm{m}$ sec- 
tions were cut from each end of the block, and sections were stained with Miller's elastic stain counterstained with van Gieson's stain and with haematoxylin and eosin. The final subpleural block $(1.5-2 \mathrm{~cm}$ in depth) was cut in serial sections at $4 \mu \mathrm{m}$ intervals, and sections were stained with the elastic stain and every tenth section was stained with haematoxylin and eosin.

As each arterial pathway was reconstructed microscopically, the external diameter and wall thickness of the vessels was measured, and the percentage arterial medial thickness calculated, from the large muscular arteries down to the precapillary vessels. ${ }^{3}$ Abnormalities of arterial wall structure such as intimal proliferation and fibrosis were documented and the position and distribution noted. The arteries were landmarked by their accompanying airway, from the large cartilaginous bronchi down to the alveoli.

In addition, on 10 blocks of tissue taken at random from the same or from both lungs the muscularity, size, and number of the peripheral pulmonary arteries were determined by quantitative morphometric techniques. ${ }^{34}$ Using at least 100 vessels pulmonary arterial muscularity was assessed by determining the mean percentage arterial medial thickness in arteries grouped according to their external diameter and by determining the proportion of muscular, partially muscular, and non-muscular arteries accompanying peripheral airways - the terminal bronchioli, respiratory bronchioli, and alveolar ducts. Furthermore, the thickness of the muscle coat along all the arterial pathways was assessed by determining the mean percentage arterial medial thickness of the arteries accompanying small preacinar airways, terminal bronchioli, respiratory bronchioli, and alveolar ducts.

To evaluate the abnormal findings, pulmonary arterial pathways were reconstructed in three normal lungs from normal patients aged 9 days and 2 and 4 months. On large populations of randomly selected arteries normal values for percentage arterial muscularity and intra-acinar arterial size and number are available for both injected and uninjected tissue, ${ }^{7-9}$ but additional unpublished data were collected for the present study. In each case on the random sections the percentage arterial medial thickness and the size of arteries accompanying peripheral airways was compared with the normal values for age using Student's $t$ test.

\section{Results}

\section{ARTERIAL MUSCULARITY}

\section{Normal lungs}

In the three normal patients aged 9 days and 2 and 4 months (cases 17-19) percentage arterial medial thickness of the axial arterial pathways was similar
(Fig. 1, Table 2). On the random sections of tissue taken from all parts of the lungs, there was no significant difference in mean percentage arterial medial thickness between the three normal lungs or between these and previously published values from normal children up to 10 years of age. ${ }^{8}$ In all three normal lungs the percentage arterial medial thickness along the main arterial pathway on the serial reconstructions was slightly higher for a given external diameter than was the mean percentage arterial medial thickness of the many arteries on the random sections.

In the three normal lungs, on the serial reconstructions the greatest percentage medial thickness occurred in arteries accompanying terminal bronchioli at the end of each arterial pathway (Fig. 2). The arteries became smaller as they approached the respiratory unit or acinus but retained a complete coat of muscle cells, and so percentage arterial medial thickness increased. The vessels beyond the level of the terminal bronchioli, although smaller, were usually only partially muscularised, had a much thinner wall, and so had a lower percentage arterial medial thickness. In none of these three normal lungs was there any intimal proliferation, fibrosis, or intimal pads along the arterial pathway or at the branching points.

\section{Ventricular septal defect (cases 1-3)}

In all three cases the serial reconstructions showed an increase in muscularity of both preacinar and intraacinar arteries (Figs. 1 and 2; Table 2). In one (case 1) muscularity was greatest in arteries one generation proximal to the terminal bronchioli (Fig. 2) and in two (cases 2 and 3 ) in arteries accompanying terminal bronchioli and the first generation of respiratory bronchioli (Table 2). There was no difference in muscularity between the axial and lateral branches of the preacinar pathway. In the patient in case 2 mild intimal proliferation occurred in several terminal bronchiolar and first generation respiratory bronchiolar arteries. Arteries showing intimal proliferation had a higher percentage medial thickness than those which did not $(22 \% v 11.5 \%)$ (uninjected tissue). In all three cases along the preacinar pathway the lateral branches arose from the parent vessel without intimal proliferation occurring at the branching points.

In all three cases microscopical examination of random sections of lung tissue from both lungs showed that the increase in, and distribution of, muscle in preacinar and intra-acinar arteries found in the serial reconstructions was similar to the changes present thoughout the lungs (Fig. 3a). In all three cases the mean percentage arterial medial thickness was significantly increased in arteries of all sizes (Fig. 1) $(p<0.001)$, and the proportion of muscularised arteries within the acinus was increased, as has previously 


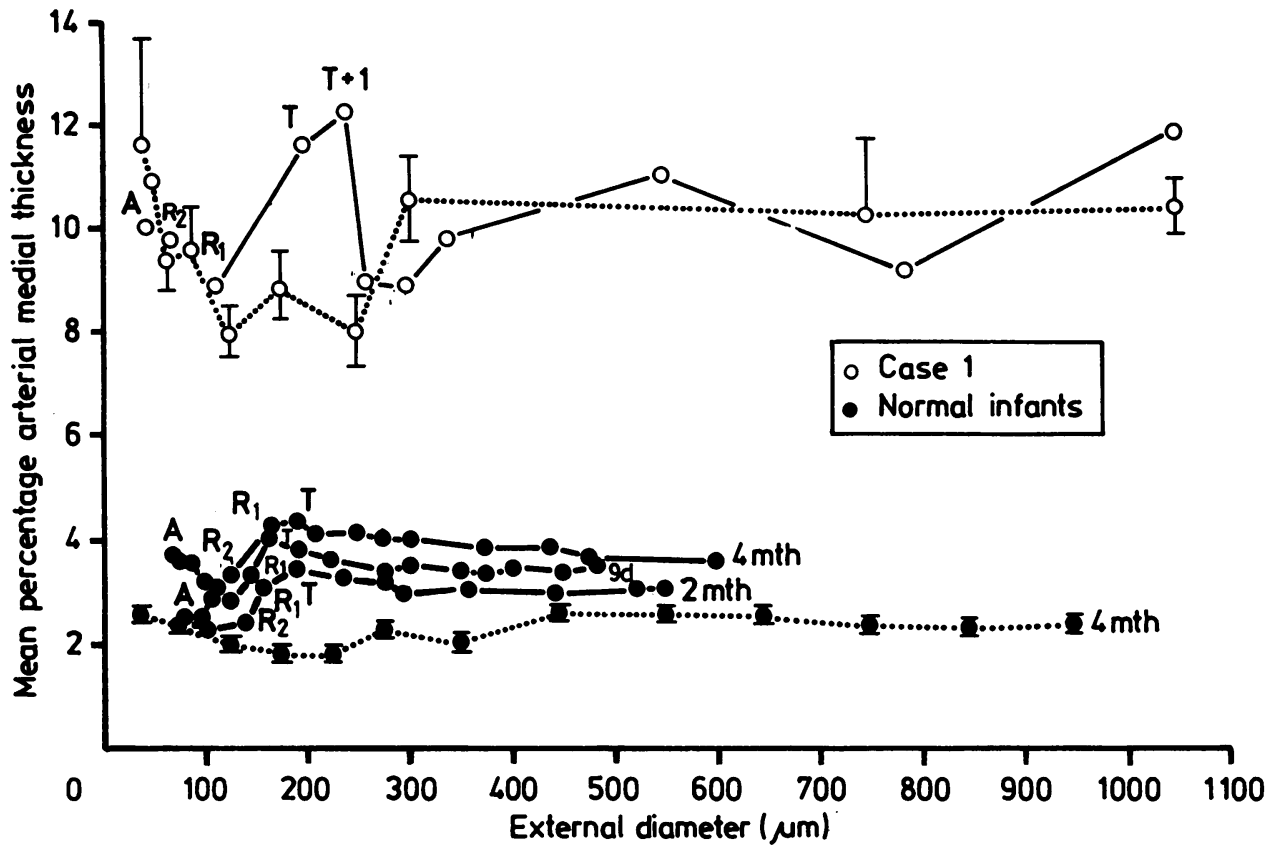

Fig. 1 Percentage arterial medial thickness in relation to external diameter ( $\mu \mathrm{m}$ ) on the serial reconstructions of normal luongs in three infants at 9 days and 2 and 4 months of age and in the patient in case 1 with a ventricular septal defect. Broken lini indicate the mean values on the random sections of a normal infant aged 4 months and the patient in case $1 . T+1$, artery accompanying an airway one generation proximal to the terminal bronchiolus; $T$, artery accompanying terminal bronchiolus; $R_{2}$ and $R_{3}$, arteries accompanying successive generations of respiratory bronchioli; $A$, artery accompanying alveolar duct. Bars represent SEM.

Table 2 Percentage arterial medial thickness of preacinar and intra-acinar arteries on the serial reconstructions. Figures are range of values along pathway

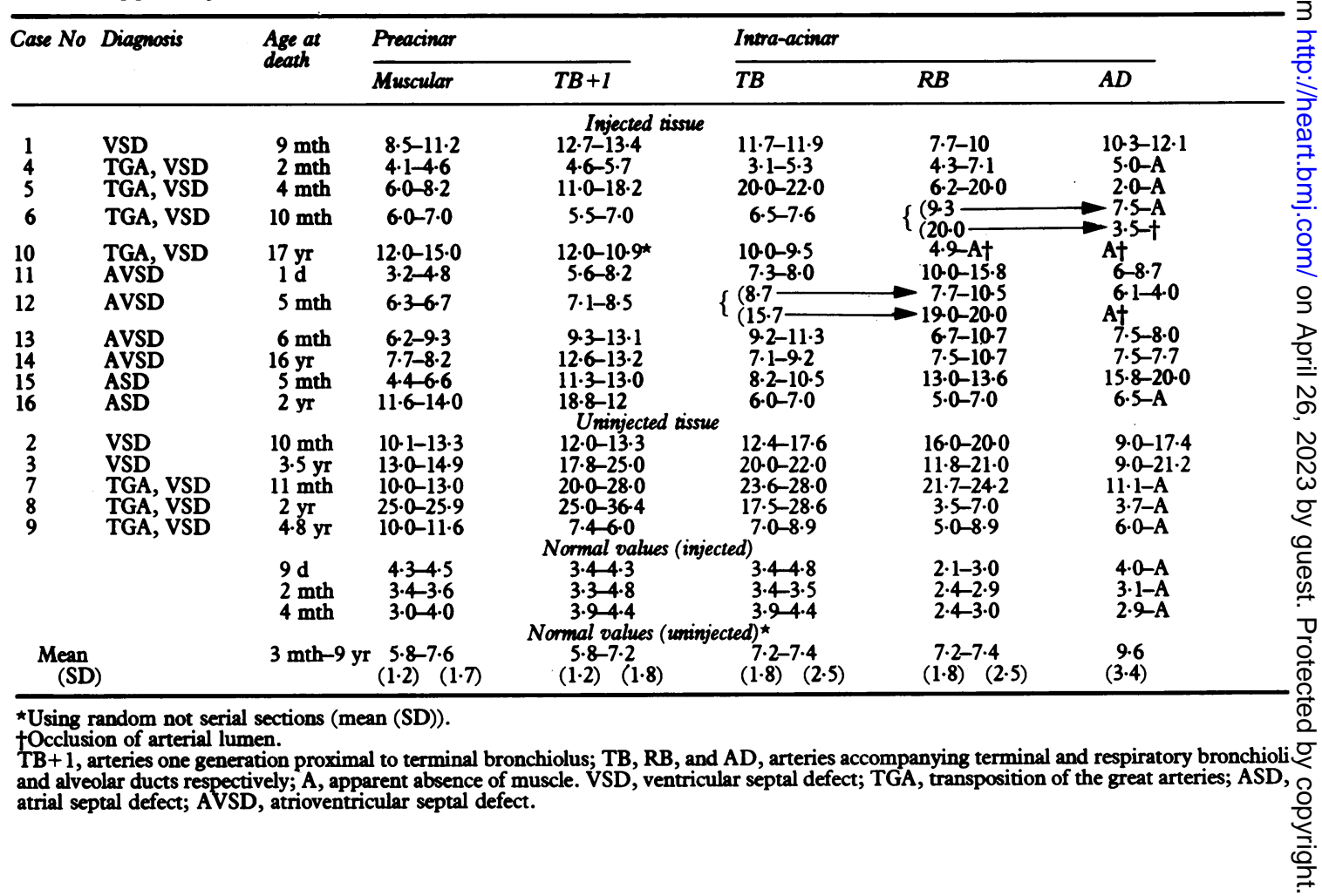




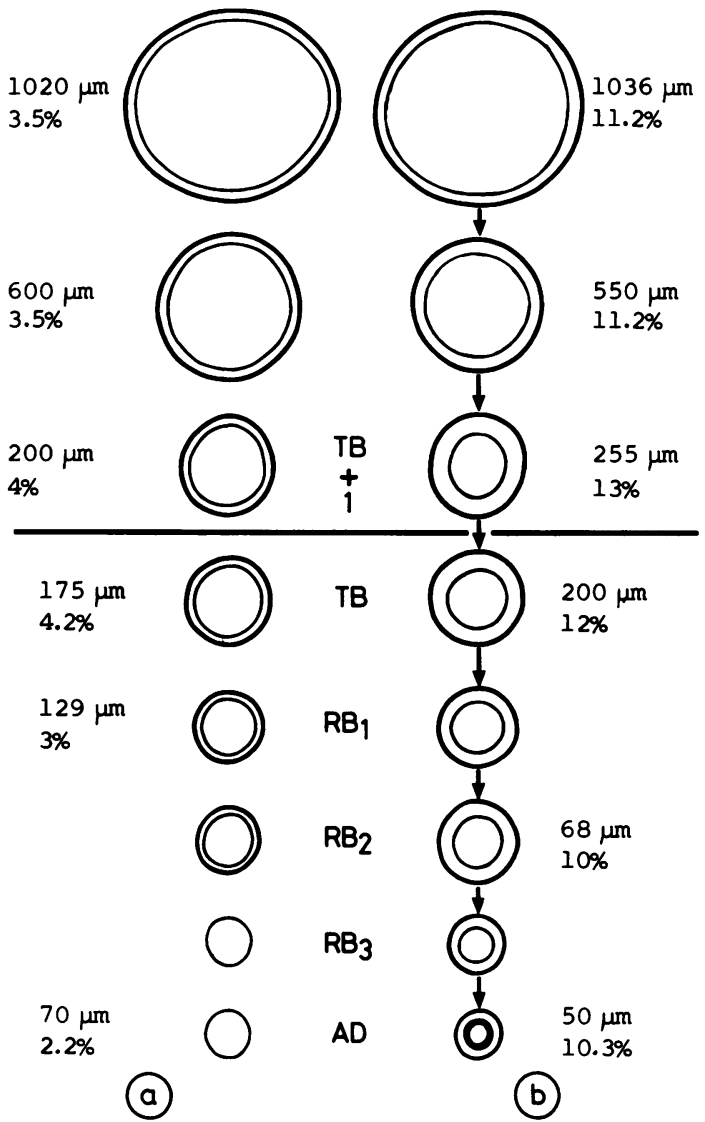

Fig. 2 Diagram of the serial reconstructions of the arterial pathways in the lung of (a) a 4 month old normal infant and (b) of the patient in case 1 with a ventricular septal defect showing the extemal diameter $(\mu \mathrm{m})$ and percentage wall thickness of meuscular preacinar and intra-acinar arteries. TB, terminal bronchiolar artery; $T B+1$, artery accompanying airway ome generation proximal to the terminal bronchiolus; $R B_{1}, R B_{2}$, and $R B_{3}$ generations of respiratory bronchioli; $A D$, alveolar duct. Horisontal line indicates end of muscular pre-acinar areerial patheway. Not drawn to scale.

been shown in patients in cases 2 and $3 .^{5}$ In one case (case 1) $87 \%$ of the arteries accompanying alveolar ducts had an entirely muscularised wall compared with the normal value of 3-8\%. In all three cases the mean percentage arterial medial thickness of arteries accompanying terminal and respiratory bronchioli and alveolar ducts was increased (Table 3). In the patient in case $2,40 \%$ of respiratory bronchiolar and $27 \%$ of alveolar duct arteries had a thin layer of circumferential intimal proliferation.

Comment-In all three patients with ventricular septal defect aged 9 months to $3 \frac{1}{2}$ years examination of serial reconstructions and random sections of lung tissue showed an increase in both preacinar and intra-acinar arterial muscle. One case showed mild intimal proliferation which might have been missed had the lung been examined histologically in life. The presence of severe medial hypertrophy in the peripheral arteries suggests, however, that if intimal proliferation is present in more proximal arteries it is not severe.

Transposition of the great arteries with ventricular septal defect (cases 4-10)

In the three patients (cases 4, 5 and 6), aged 2-10 months of age, the pulmonary arterial systolic pressure was similar to the systemic systolic pressure. The serial reconstructions showed similar structural abnormalities in all three but they were the least pronounced in the youngest (case 4). The percentage wall thickness of the preacinar arteries larger than $200 \mu \mathrm{m}$ in diameter was increased and there was an abrupt and pronounced further increase in muscularity in the smaller arteries just proximal to the acinus or accompanying the terminal bronchiolar and first generation of respiratory bronchioli (Table 2, Fig. 4) Beyond this hypertrophied region the arteries had a lower relative wall thickness and were frequently only partially muscularised, dilated, and irregular in shape. Intimal proliferation occurred in two patients (cases 5 and 6 ) but unlike the patient in case 2 with a ventricular septal defect in these patients most of the arteries entering the acinus were affected. Intimal proliferation was found in arteries showing the greatest relative wall thickness, involved only a short segment of each pathway, and was strategically placed to obstruct blood flow, proximal to or just within the acinus at the end of each arterial pathway (Fig. 5). Intimal proliferation occurred more frequently and was more severe in the patient in case 6 than in that in case 5 and occluded some respiratory bronchiolar and alveolar duct arteries where a thick layer of intimal proliferation was associated with a reduction in medial thickness. Along the preacinar arterial pathway in two patients (cases 5 and 6) intimal proliferation partially and occasionally completely occluded the origin of many of the lateral branches.

Microscopical examination of tissue taken at random from both lungs showed that in all three cases the findings in the serial reconstructions were similar to the structural abnormalities present throughout both lungs (Figs. 3b, 6, and 7). In all three cases, mean percentage arterial medial thickness was significantly greater than normal in arteries of all sizes $(p<0.01)$ (Fig. 8). In all three cases mean percentage arterial medial thickness of arteries accompanying each type of peripheral airway was increased (Table 3). Nevertheless, the proportion of muscular, partially muscular, and non-muscular arteries at each airway 

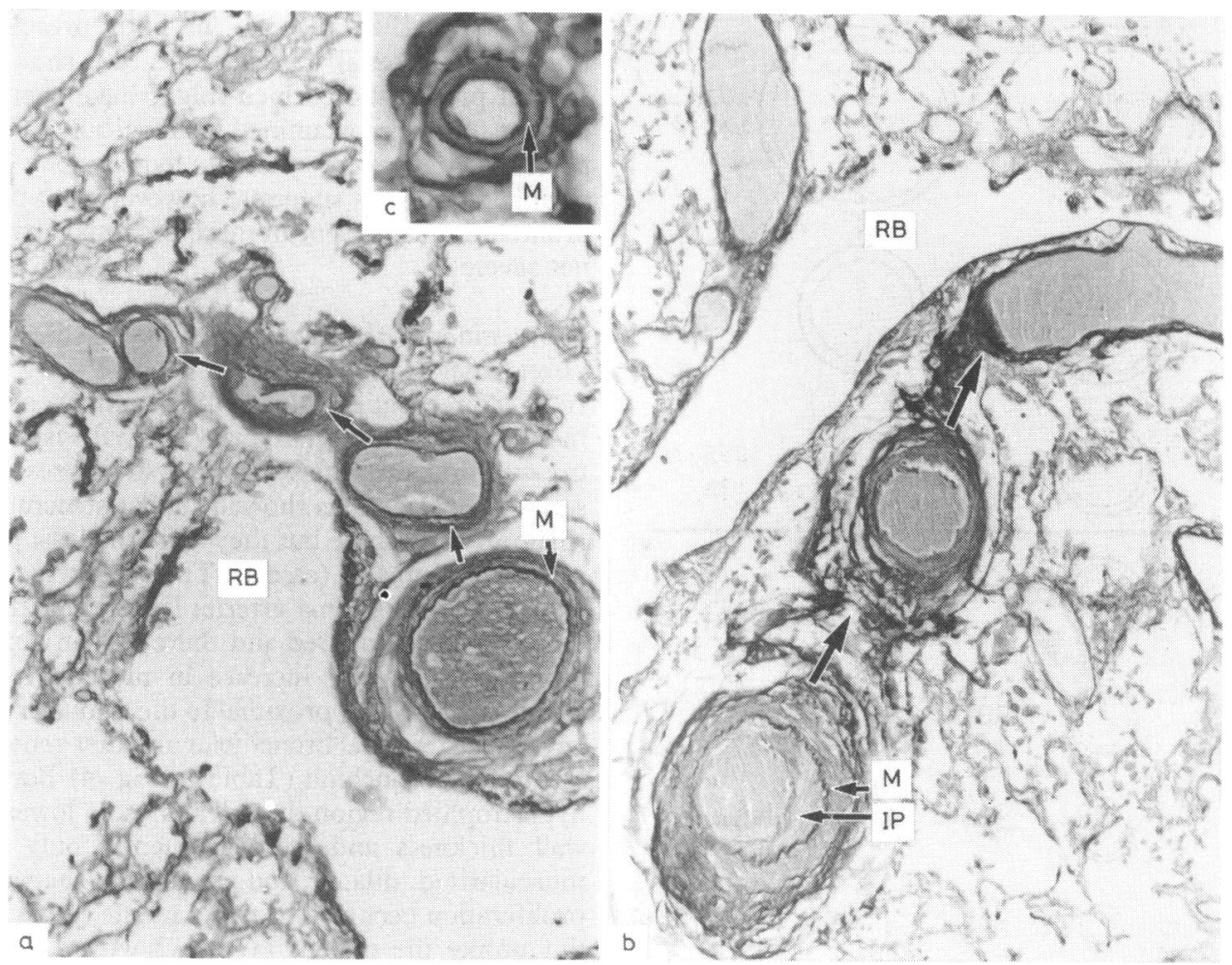

Fig. 3 Photomicrographs from (a) an infant with ventricular septal defect aged 10 months and (b) an infant with transposition of the great arteries and ventricular septal defect aged 4 months showing arteries at the same position along the arterial pathway at the same magnification $(\times 200)$. In $(a)$ an artery accompanying a terminal bronchiolus and its branches has a thick media $(M)$ as do the alveolar wall arteries shown in $(c)$. In $(b)$ the lumen of a terminal bronchiolar artery is narrowed by a thick media (M) and intimal proliferation (IP), and this ultimately leads to thin walled arteries. $R B$, respiratory bronchiolus. (Miller's elastin stain, counterstained with van Gieson's stain.)

level was normal, indicating that muscle had not extended towards the capillary bed. In the patient in case 6 plexiform lesions were found in some of the random sections in addition to the intimal proliferation found on the serial reconstructions.

In contrast to the patients in cases 4,5 , and 6 , in those in cases 7,8 , and 9 the pulmonary arterial pressure was normal or only moderately increased, but in each case the pulmonary blood flow was or had been increased (Table 1). In all three cases the serial reconstructions using uninjected material showed an increase in percentage arterial medial thickness in arteries larger than $300 \mu \mathrm{m}$, and on random sections of uninjected tissue a similar increase in muscularity was statistically significant $(p<0.001)$ and relative wall thickness was approximately 2.3 times greater than normal. ${ }^{9}$ As in the patients in cases 4,5 , and 6 , in those in cases 7 and 8 the serial reconstructions showed an abrupt increase in wall thickness in arteries accompanying terminal and first generation respirat- ory bronchioli (Table 2), and examination of both serial and random sections showed an increase in percentage arterial medial thickness in arteries smaller than $300 \mu \mathrm{m}$ in diameter using random sections $(\mathrm{p}<0.001)$. By contrast, in one patient (case 9) with a normal postoperative pulmonary arterial pressure and flow the muscularity of the peripheral arteries $<300 \mu \mathrm{m}$ in diameter was normal. In all three cases on the random sections the mean percentage medial thickness of arteries accompanying each type of intra-acinar airway was increased (Table 3). The distribution of muscle along the arterial pathway was normal, as in the patients in cases 4-6. Examination of both serial and random sections showed intimal proliferation in one patient (case 7) at the branching points of muscular preacinar arteries and in respiratory bronchiolar and alveolar duct arteries, many of the latter being occluded by intimal proliferation. In the patient in case 9, mild intimal fibrosis occurred in the same types of vessel $1 \frac{1}{2}$ years after a Mustard repair. 
Table 3 Mean percentage arterial medial thickness of arteries accompanying peripheral airways in random sections

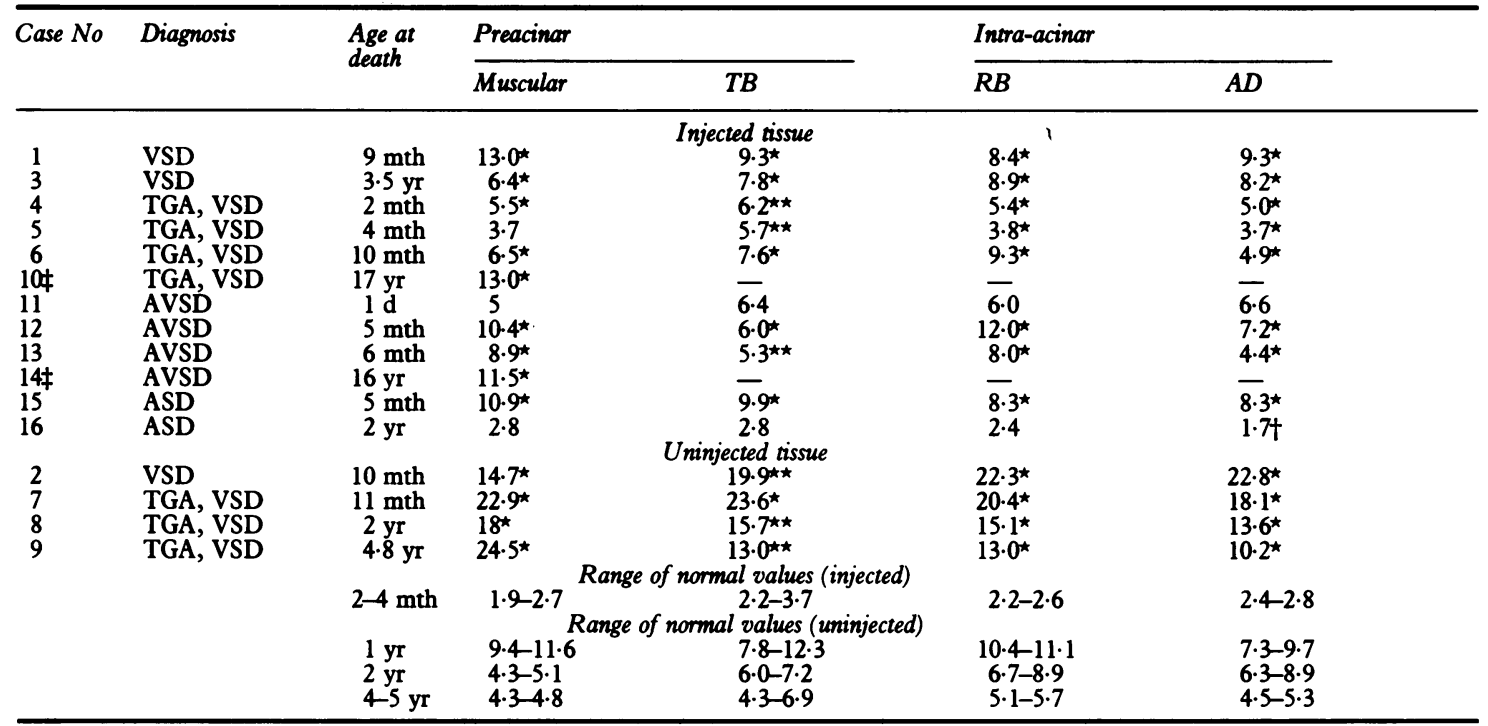

IIntra-acinar arteries so damaged by occlusive intimal fibrosis or medial atrophy and dilatation that measurements are meaningless. When each case is compared with own normal for age, significant increase indicated by ${ }^{\star} p<0.001 ; \star \star p<0.01$; findicates significant reduction, $\mathrm{p}<0.001$. No age matched comparison available for case 11 .

VSD, ventricular septal defect; TGA, transposition of the great arteries, AVSD, atrioventricular septal defect.

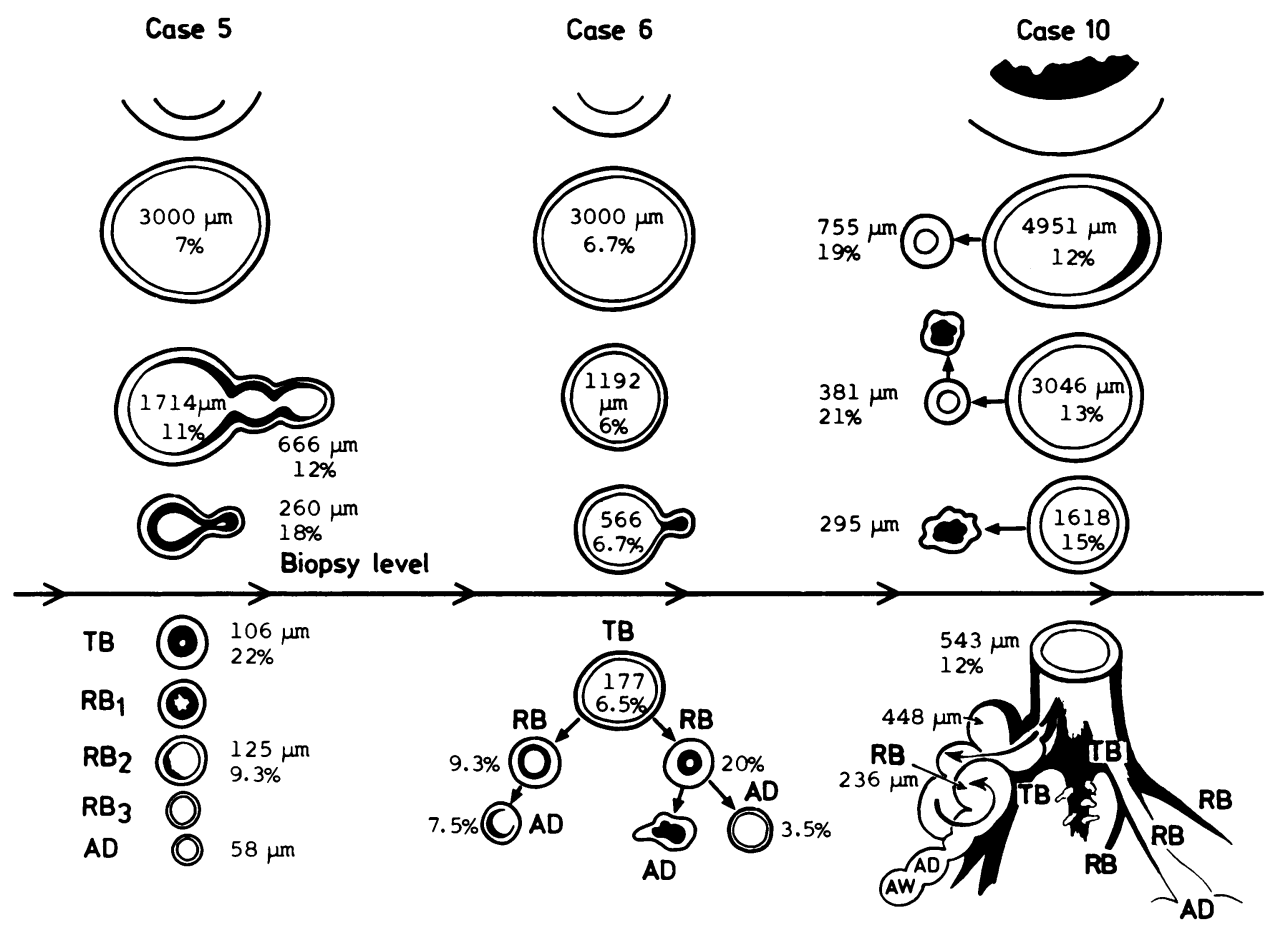

Fig. 4 Diagrams of serial reconstruction of the pulmonary arterial pathways in the patients in cases 5, 6, and 10, from the elastic to the muscular preacinar arteries, terminal bronchiolar (TB), successive generations of respiratory bronchiolar $\left(R B_{1}, R B_{2}, R B_{3}\right)$, and alveolar duct arteries $(A D)$. The extermal diameter ( $\left.\mu m\right)$ and percentage wall thickness of the arteries is shown. The line indicates those peripheral arteries likely to be included in a lung biopsy specimen. Black areas within lumen indicate intimal proliferation and fibrosis, which occludes the lumen of some vessels in the patients in cases 6 and 10. 


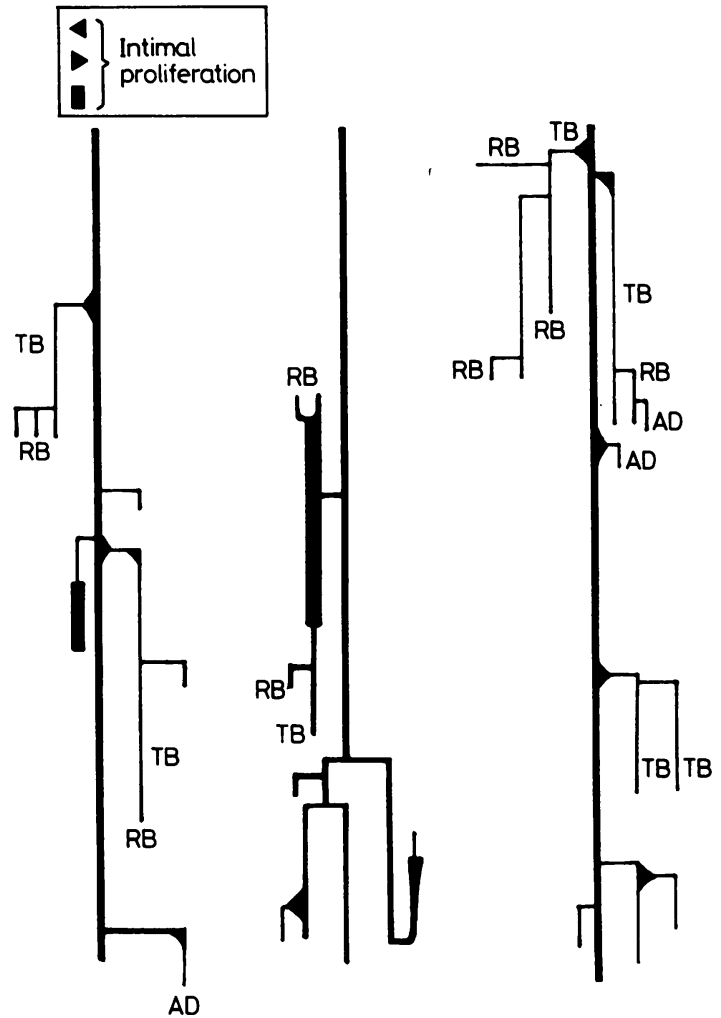

Fig. 5 Diagrams of three pulmonary arterial pathways reconstructed in the patient in case 5. The relative thickness of the vertical lines indicates the thickness of the media. $A D$, arteries accompanying alveolar ducts; $R B$, arteries accompanying respiratory bronchioli; $T B$, arteries accompanying terminal bronchioli.

In the patient in case 10 , aged 17 years, the large elastic arteries showed atheromatous change. The preacinar vessels showed eccentric and circumferential intimal fibrosis, usually associated with branching, and many lateral branches were occluded by intimal proliferation and fibrosis (Fig. 4). Terminal bronchiolar and respiratory bronchiolar arteries were frequently occluded by intimal fibrosis and recanalised by capillary channels (Fig. 4). Random sections showed the classical changes of advanced pulmonary vascular obstructive disease. Fig. 8 shows that the normal relation between percentage arterial medial thickness and arterial size was absent. Preacinar arteries $>\mathbf{4 0 0} \mu \mathrm{m}$ in diameter showed a pronounced increase in muscularity, but many of the more peripheral arteries were dilated and so had a diameter of $>400 \mu \mathrm{m}$, and because they had medial atrophy they had a low percentage medial thickness.

Comment-In seven cases of transposition of the great arteries with ventricular septal defect the structural abnormalities found on the serial reconstructions were similar to those found on the random sections, and the changes found in the preacinar arteries of the serial reconstructions explained those seen in the intra-acinar arteries of both serial and random sections. In cases with pulmonary hypertension medial thickness was greatest over a relatively short segment of the arterial pathway at the end of the preacinar pathway or just within the acinus, and intimal proliferation was present most often and to the greatest extent within this region. Had a peripheral lung biopsy specimen been obtained from the patients in cases 5 and 6, or even in case 7, which did not include small preacinar or terminal bronchiolar arteries showing intimal proliferation, the presence of only a slight increase in intra-acinar arterial muscularity could have given a mistakenly favourable impression. In such cases, however, the arteries frequently had an irregular shape. When determined, an increase in pulmonary vascular resistance was seen to be associated with obstruction to blood flow strategically placed at the end of each pathway and not with widespread obliterative disease. One patient (case 10) had the classical changes of advanced pulmonary obstructive disease and the abnormalities would have been evident in a lung biopsy specimen. This case also shows how with time the muscularity of the preacinar arteries increases and that of the intra-acinar arteries decreases as a result of atrophy.

\section{Atrioventricular septal defects (cases 11-14)}

In one patient (case 11), aged 1 day, the serial reconstructions showed a lower percentage arterial medial thickness along the pre-acinar pathway than in those in cases 12-14, but the muscularity of the intra-acinar arteries was similar and greatest in respiratory bronchiolar arteries. The findings in the patients in cases 12 and 13, aged 5 and 6 months respectively, resembled those in the two in cases 5 and 6, children of similar age with transposition of the great arteries and ventricular septal defect, the lungs showing a similar increase in arterial muscularity and the presence of intimal proliferation (Table 2; Fig. 9). On the random $D$ sections, in each of the three cases the structural abnormalities were similar to those found on the serial $N$ reconstruction. In one patient (case 11), at 1 day of age, mean percentage arterial medial thickness in arteries less than $250 \mu \mathrm{m}$ in diameter was similar to that of stillborn infants, suggesting that the arteries had not adapted normally to extrauterine life (Fig. 10). ${ }^{7}$ In the patients in cases 12 and 13 the mean percentage arterial medial thickness was significantly greater than normal in arteries $>250 \mu \mathrm{m}$ in diameter ( $<<0.001)$, but was normal in arteries $<75 \mu \mathrm{m}$ in diameter, those arteries lying distal to thick walled 


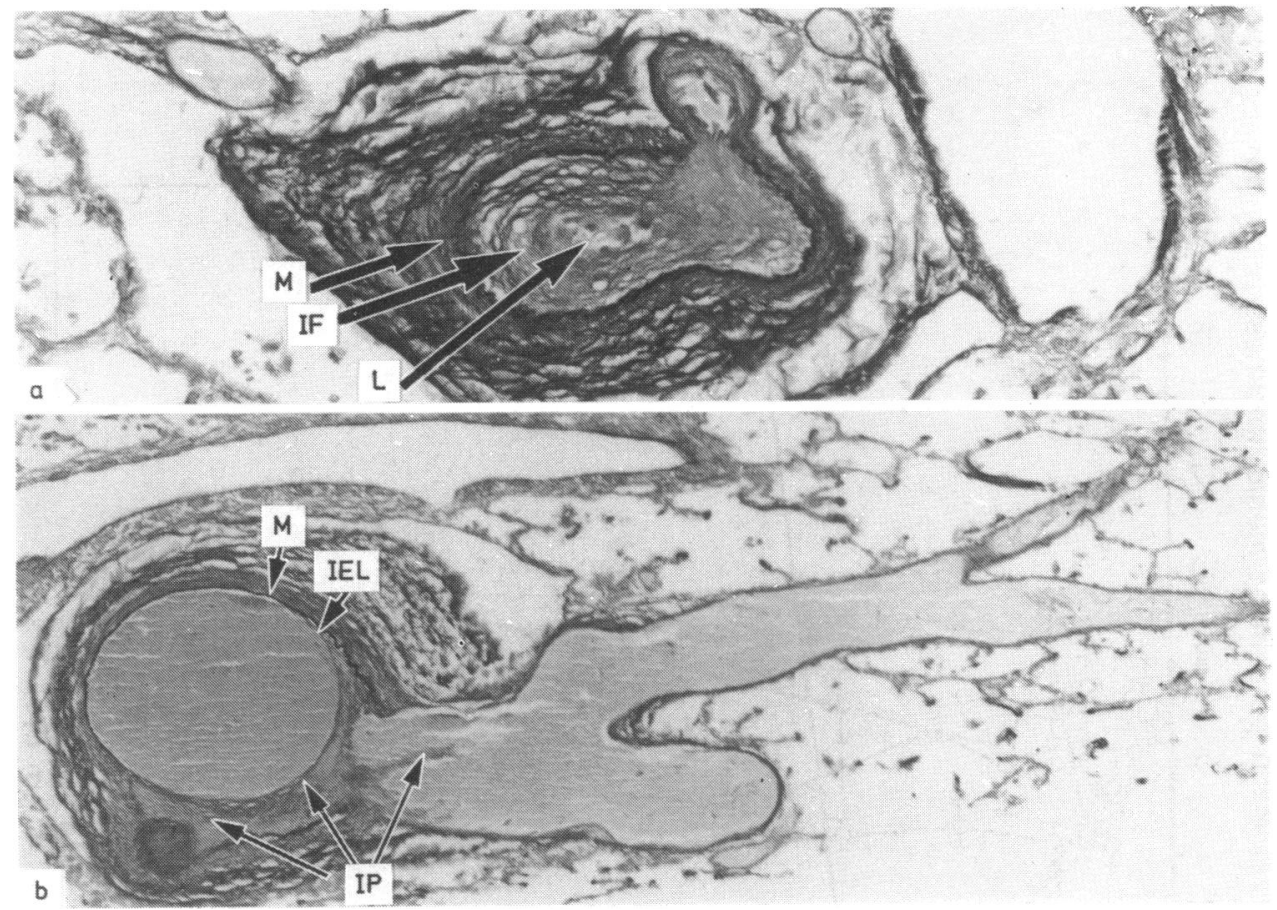

Fig. 6 Photomicrographs from the patient in case 5 aged 5 months with transposition of the great arteries and ventricular septal defect showing (a) small preacinar muscular arteries whose lumen $(L)$ is almost occluded by a thick media (M) and intimal fibrosis (IF). (Magnification $\times 190$, Miller's elastin stain counterstained with van Gieson's stain.) (b) A terminal bronchiolar artery distended by injection medium having a thick media $(M)$ and lying internal to the internal elastic lamina (IEL) intimal proliferation (IP) surrounds the origin of thin walled branches. (Miller's elastin stain counterstained with van Gieson's stain.)

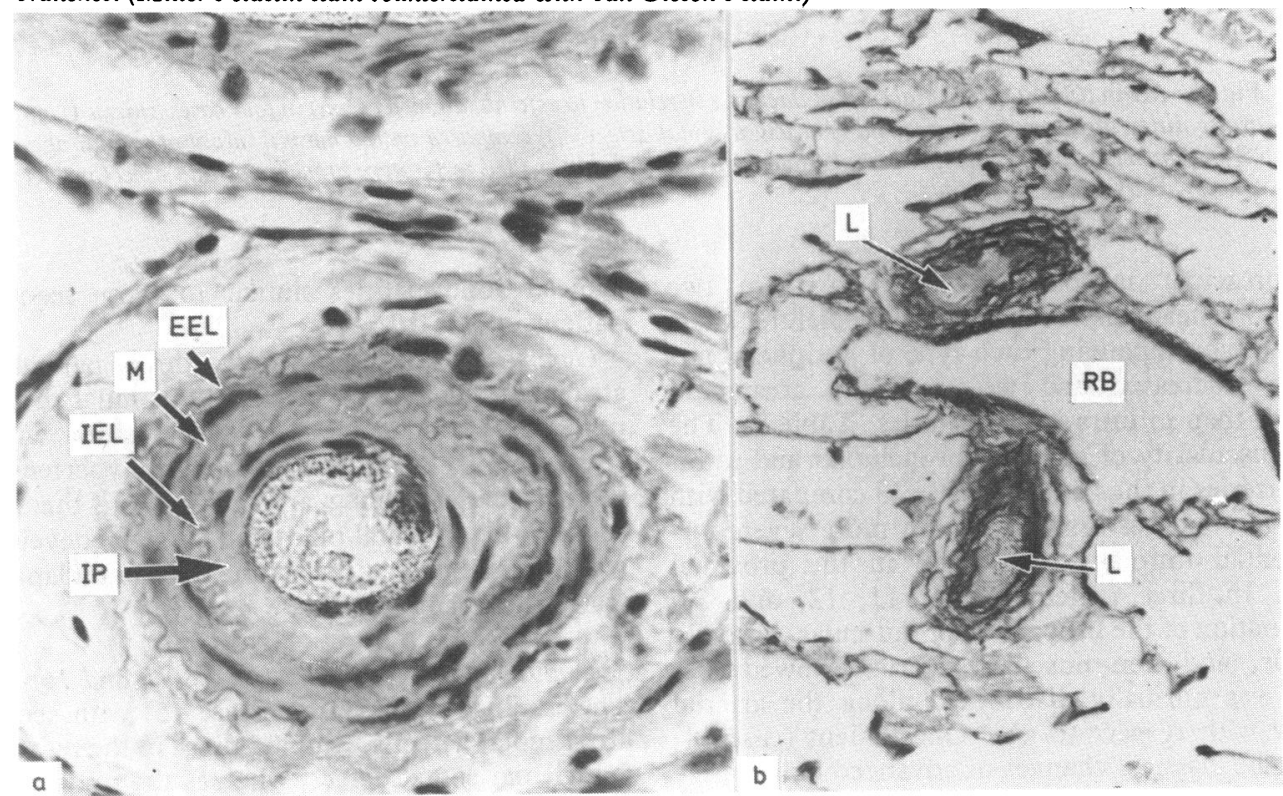

Fig. 7 Photomicrographs from the patient in case 6 with transposition of the great arteris and ventricular septal defect aged 10 months showing (a) a small muscular artery with a thick layer of muscle cells composing the media (M) lying between external (EEL) and internal elastic lamina (IEL). A thick layer of circumferential intimal proliferation $(I P)$ narrows the lumen of this injected artery. (Magnification $\times 950$, haematoxylin and eosin.) (b) Two injected arteries accompanying a respiratory bronchiolus $(R B)$ whose lumen $(L)$ is almost occluded by intimal proliferation and fibrosis. (Magnification $\times 208$, Miller's elastin stain counterstained with van Gieson's stain.) 


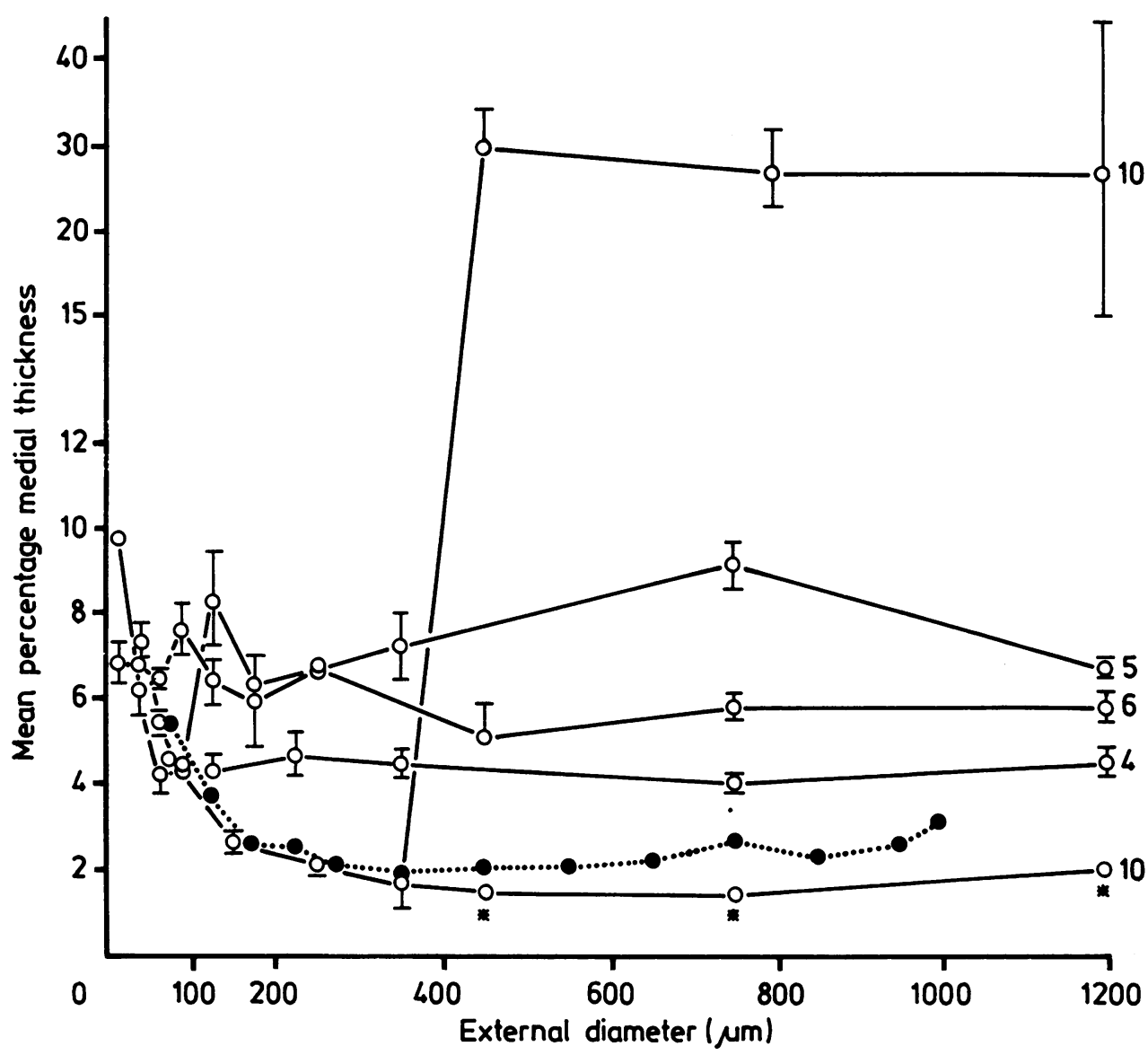

Fig. 8 Mean percentage arterial medial thickness in relation to external diameter ( $\mu m$ ) in four cases (injected) of transposition of the great arteries and ventricular septal defect $(O)$ compared with a normal infant of similar age (O). Numbers indicate case numbers. ${ }^{\star}$ Abnormally dilated thin walled respiratory bronchiolar and alveolar duct arteries. Bars represent SEM.

small preacinar muscular arteries. In these two patients the mean percentage arterial medial thickness of arteries accompanying each type of peripheral airway was increased and was generally greater in preacinar than in intra-acinar arteries (Table 3). The lower muscularity of terminal bronchiolar and intraacinar arteries in the patient in case 13 compared with that in case 12 was associated with more severe circumferential intimal proliferation in the proximal arteries. In three patients (cases 11,12 , and 13) determination of the proportion of muscular, partially muscular, and non-muscular arteries showed that muscle was normally distributed,along the arterial pathway with respect to age. One patient (case 14) showed the classical changes of advanced obliterative pulmonary vascular disease, and the findings on the serial reconstruction and on the random section showed abnormalities similar to those seen in the patient in case 10 .

Comment-The findings in three patients with atrioventricular septal defect were similar to those in patients of similar age with transposition with ventricular septal defect and pulmonary hypertension. In the one patient dying at 1 day of age the findings suggest that prenatal pulmonary arterial development was normal but that the arteries had not adapted normally to extrauterine life.

Secundum atrial septal defect (cases 15 and 16)

The findings in the infant (case 15) with secundum atrial septal defect resembled those in the infants with ventricular septal defect, whereas the findings in the older infant (case 16) resembled those in infants with transposition of the great arteries and ventricular sep- 


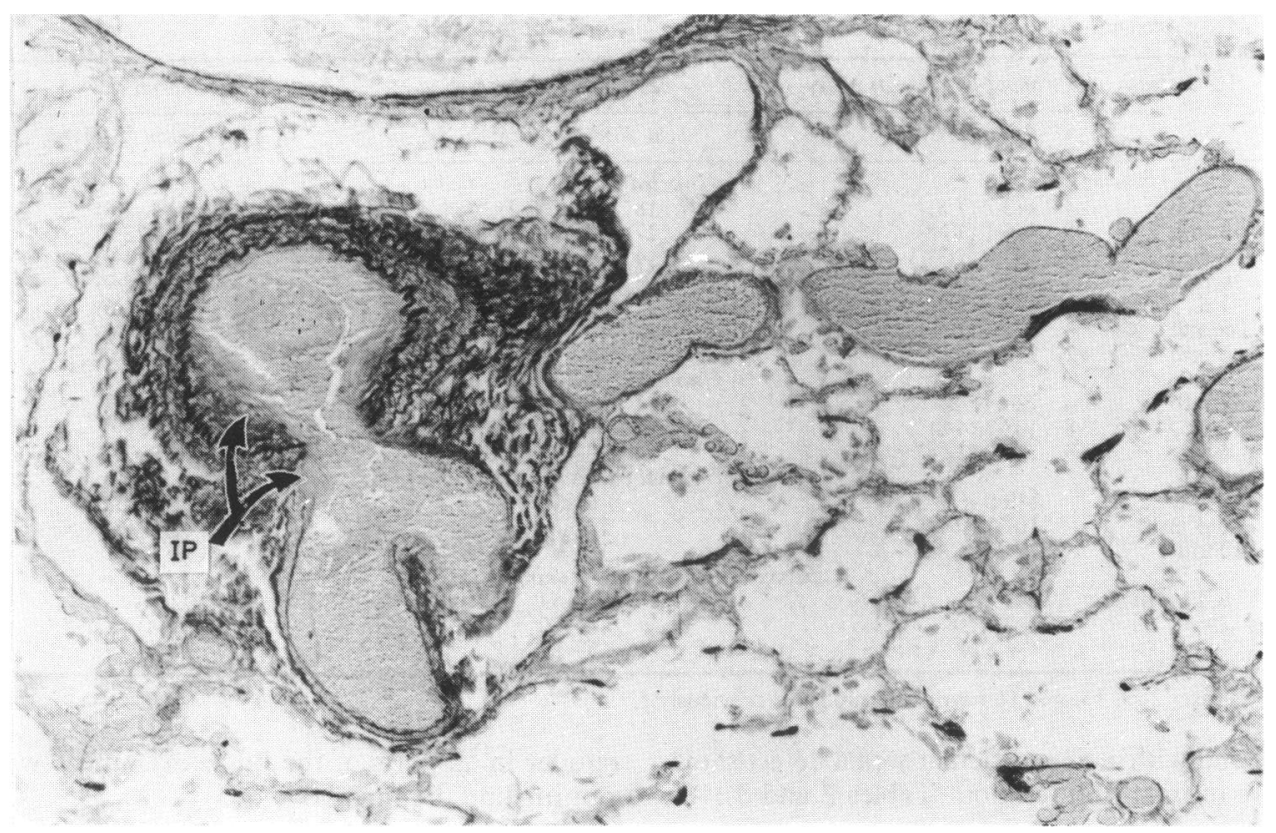

Fig. 9 Photomicrograph from the patient in case 13 with an atrioventricular septal defect, aged 6 months, showing a small muscular artery with intimal proliferation (IP) narrowing the lumen at the origin of the thin walled branches. (Magnification $\times 190$, Miller's elastin stain counterstained with van Gieson's stain.)

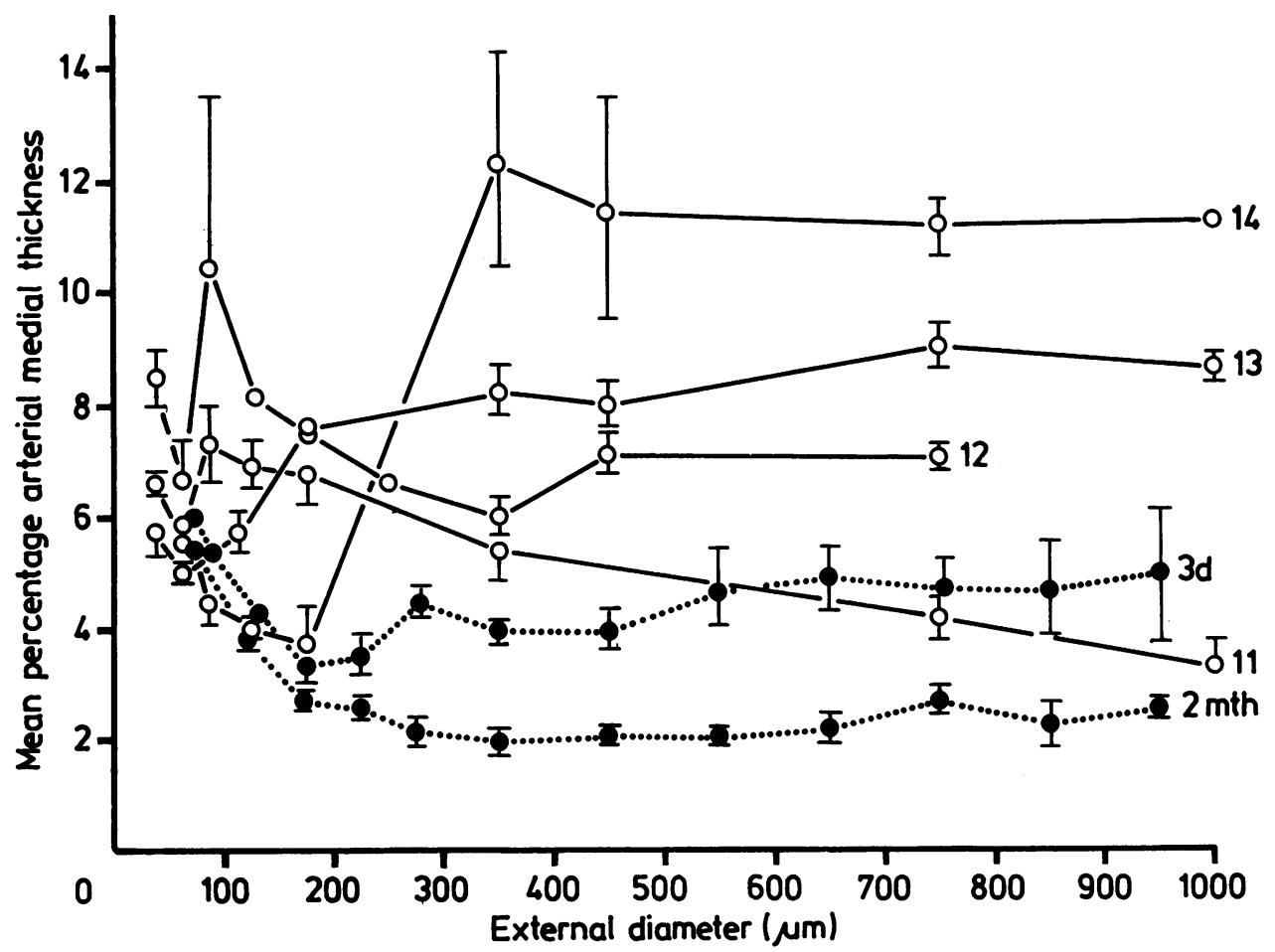

Fig. 10 Mean percentage arterial medial thickness in relation to external diameter ( $\mu \mathrm{m})$ in four patients with atrioventricular septal defect $(O)$ compared with the normal at three days and at two months $(\bullet)$. Numbers indicate case numbers. Bars represent SEM. 
Table 4 Mean external diameter ( $\mu \mathrm{m}$ ) of arteries accompanying peripheral airways

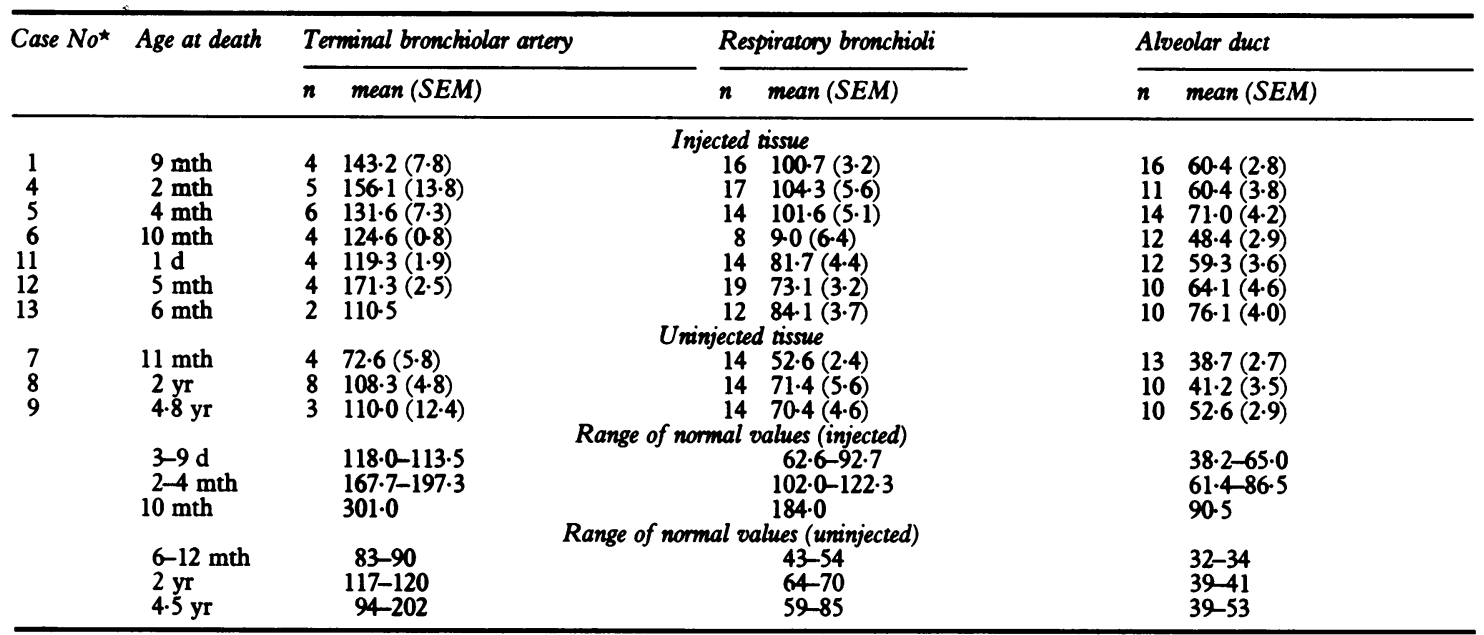

$\star$ The data on cases $2,3,15$, and 16 have been published previously. ${ }^{56}$

tal defect and with atrioventricular septal defect showing severe intimal proliferation (Tables 2 and 3).

\section{Size and number of intra-acinar arteries on random sections}

The mean external diameter was normal in four cases, at the lower limit of the normal range in three, and below normal in seven cases (Table 4). The cases with the smallest arteries were generally those with the greatest increase in muscularity. Two patients (cases 10 and 14) showed such destruction of the intra-acinar arteries that measurements of the external diameter of these vessels were meaningless. The alveolar to arterial ratio was normal in 13 cases, varying between 9.4 and 14.3 (normal 9.2-14.3 depending on age). ${ }^{9}$ The ratio was increased for age in two patients (cases 2 and 6), being 14.0 and 20.1 respectively, indicating a reduction in the number of intra-acinar arteries. In one patient (case 10) a low ratio of 5.4 was due to the impossibility of excluding arteries in the dilatation lesions from the count.

\section{VEIN WALL STRUCTURE}

Vein wall thickness appeared normal or only slightly increased in all patients with transposition of the great arteries with ventricular septal defect and atrioventricular septal defect, except in three (cases 10, 12, and 14) in whom it was increased. In the older patients (cases 10 and 14) thick walled veins showed intimal fibrosis. Vein wall thickness was increased and the small veins were "arterialised" in the three patients with ventricular septal defect and in one (case 16) with a secundum atrial septal defect and was nor$\mathrm{mal}$ in the patient in case 15.56

In all 16 cases the structural abnormalities were similar in all parts of the lungs examined, which did not include the lingula.

\section{Discussion}

In young children with congenital heart disease and pulmonary hypertension the criteria for the selection of patients suitable for an intracardiac repair are less certain than in older patients and adults. ${ }^{2}$ Two factors must be considered: firstly, the severity of medial hypertrophy, intimal proliferation, and fibrosis and, secondly, any reduction in intra-acinar arterial size and number which would increase the work of the pulmonary venous ventricle immediately after the repair. In addition, a pronounced increase in pulmonary vascular smooth muscle may be associated with pulmonary hypertensive crises in the postoperative period. ${ }^{10}$ If the patient survives the operation, the potential reversibility of the different types of pathological abnormalities determines ultimate survival. In the patients in cases $4,7,8$, and 9 the pulmonary vascular changes were unlikely to have contributed to the operative death, but the severe medial hypertrophy seen in the patients in cases $1,2,3,5$, and 12 associated with intimal proliferation in two (cases 5 and 12) probably did do so, although all the pathological lesions present are considered to be potentially reversible. In three patients (cases 1-3) the pulmonary $c$ arteriolar resistance was low but was 14.8 units $\mathrm{m}^{2}$ in the patients in case 5 and not determined in that in case 12 . Three patients (cases 6,13 , and 16) showed severe obstructive and occlusive intimal proliferation and fibrosis associated with a pulmonary arteriolar resistance of at least 16.5 units $\mathrm{m}^{2}$ in air, and the structural abnormalities were not potentially revers- 
ible. Four patients died without an intracardiac repair, two having severe and potentially irreversible pulmonary vascular disease.

By studying serial reconstructions of the lungs of children dying with pulmonary hypertension the structural abnormalities in the peripheral arteries could be related to and explained by the abnormalities occurring in the more proximal arteries which are frequently not sampled in a lung biopsy. This study emphasises how different structural abnormalities relate to each other and the danger of considering individual findings in isolation.

In the present study the lungs of three children with an isolated ventricular septal defect all showed a pronounced increase in muscularity in both preacinar and intra-acinar arteries, extending almost to the capillary bed, and intimal proliferation was infrequent and mild. But in pulmonary hypertensive cases of transposition with ventricular septal defect and in those of atrioventricular septal defect $>2$ months of age an abrupt reduction in wall thickness occurred distal to a thick walled muscular arterial segment containing circumferential intimal proliferation and having a narrowed lumen. In these cases, therefore, the modest increase in muscularity was not a favourable sign but indicated severe proximal obstruction to blood flow even in children aged $\leqslant 10$ months. The length of the obstructed pathway tended to be longer the older the child (Fig. 4). Any lung biopsy specimen will usually include many alveolar wall arteries, some alveolar duct arteries, fewer respiratory bronchiolar arteries, and much less frequently terminal bronchiolar and small preacinar muscular arteries. It is possible, therefore, that a lung biopsy specimen from a patient with pulmonary hypertension and an increased pulmonary vascular resistance may show little increase in intra-acinar arterial muscularity without there being more proximal arteries present to help interpret that observation. In young children with pulmonary hypertension the media may have a fairly normal appearance and is not associated with excessive deposition of elastin, is of even thickness, and is often not associated with plexiform lesions as in older patients. In the present study plexiform lesions were present in only one out of nine cases $<1$ year of age. These observations emphasise the caution with which lung biopsy specimens taken from young children must be interpreted.

This study also illustrates how the appearance of an artery at one point in the arterial pathway will differ in appearance from arteries more proximal or distal to it. In a lung biopsy specimen differences in arterial structure are to be expected, and each artery must be identified according to its accompanying airway. The appearance of all arteries at each airway level are considered together rather than the appearance of all arteries present in a biopsy specimen being assessed as is sometimes done, for example, by determining the percentage of all arteries showing intimal proliferation.

The relation between pulmonary arterial muscularity, pressure, and resistance probably differs in different types of congenital heart disease. In the present study all the patients with ventricular septal defect and with transposition and ventricular septal defect had a pulmonary arterial pressure similar to the systemic arterial pressure, except one, and muscularity was lower in both preacinar and intra-acinar arteries in those with transposition and ventricular septal defect than in those with an isolated ventricular septal defect. Yamaki and Wagenvoort also noted a "clear trend" for the mean arterial medial thickness to be greater in patients with an isolated ventricular septal defect than in those with transposition and ventricular septal defect at any level of pulmonary arterial pressure and at any age. ${ }^{11}$ When an individual lung biopsy specimen is interpreted, therefore, values of percentage arterial medial thickness must be considered in relation to the appearance of media and intima in the different types of arteries present in the biopsy specimen, to the possible changes in arteries not included in the sample, and to the difference in natural history of pulmonary vascular disease in different types of congenital cardiac anomalies. This study also emphasises the difficulties inherent in using a grading system to evaluate the severity of disease and predict operative outcome. ${ }^{12}$

In lung biopsy studies the thickness of the pulmonary arterial media increases as the pulmonary arterial pressure rises. ${ }^{1}$ The present study, however, shows that severe pulmonary hypertension may be associated with only a moderate increase in medial thickness at a time when the lung does not show the classical changes of medial atrophy, intimal fibrosis, and the dilatation lesions characteristic of advanced pulmonary vascular disease. ${ }^{2}$ When determined, pulmonary vascular resistance was increased in such cases, presumably as a result of the obstruction to blood flow strategically placed at the end of each arterial pathway and not to advanced obliterative pulmonary vascular disease. The relation between percentage arterial medial thickness and pulmonary arterial pressure and resistance needs to be re-evaluated by studying pulmonary vascular structure in each type of congenital heart disease separately, rather than by studying the relation in a group of different abnormalities, as previously.

In this study the size and number of intra-acinar arteries were determined in addition to arterial muscularity. The mean external diameter of arteries accompanying intra-acinar airways was at the lower limit of the normal range or below in all except four cases. 
The greatest reduction in size occurred in cases showing the greatest increase in muscularity of both preacinar and intra-acinar arteries, the cases of ventricular septal defect. On the serial reconstructions, in all the types of congenital heart disease studied, the external diameter of injected arteries tended to become smaller when the medial thickness of the vessel increased and became larger more distally when the wall was thinner. The reduction in external diameter may be due to increased tone, even in arteries distended by injection after death. Severe medial hypertrophy and sustained contraction might also impair growth. The number of intra-acinar arteries in all the pulmonary hypertensive patients of $\leqslant 3 \frac{1}{2}$ years of age was normal in all but two infants, one with a ventricular septal defect and one with transposition and ventricular septal defect. In the patient with a ventricular septal defect a severe reduction in lumen diameter might have caused permanent occlusion of the lumen, as has been reported in primary pulmonary hypertension, ${ }^{13}$ or have prevented injection material from filling the smallest arteries. In the patients with transposition and ventricular septal defect arteries occluded by intimal proliferation were seen. The finding of a normal number of intraacinar arteries in children with an increase in pulmonary vascular resistance differs from the study of Rabinovitch $e t a l,{ }^{1}$ in which all cases with a resistance $\geqslant 3.5 \mathrm{units} / \mathrm{m}^{2}$ showed a reduction in number. The relation between growth and occlusion of arteries in children with pulmonary hypertension needs further study.

A lung biopsy specimen must be representative of the entire pulmonary vasculature. The findings in this and other studies suggest that in children with congenital heart disease and pulmonary hypertension there are no significant regional differences in pulmonary vascular structure, except possibly for the lingula, ${ }^{14} 15$ and therefore the surgeon should be able to obtain a biopsy specimen in any area except the lingula with impunity. Nevertheless, the present study shows that the depth of the biopsy specimen is crucially important (Fig. 4), and a sliver of subpleural tissue containing only alveolar duct and alveolar wall arteries may be useless or even misleading.

It is not clear why the lungs should react differently in different types of congenital heart disease. In cases of ventricular septal defect with an increase in muscularity along the entire length of the arterial pathway adaptation to extrauterine life may be slow and incomplete, enabling the muscularity of the arterial pathway to increase meanwhile. By contrast, in cases of transposition with ventricular septal defect and large atrioventricular septal defect it is as though the lung adapted normally to extrauterine life and became damaged by doing so. Perhaps in ventricular septal defect the lung is able to control the magnitude of the pulmonary blood flow, whereas in transposition with ventricular septal defect it does not do so, and therefore the small pre-acinar and terminal bronchiolar arteries are injured when they are at their most vulnerable. These are the arteries which in the normal lung dilate rapidly after birth. ${ }^{16}$

In the normal lung the small muscular arteries are thought to be the major site of resistance to blood flow. The present study has shown that in the normal lung the small preacinar muscular and terminal bronchiolar arteries have a slightly higher relative wall thickness than the more proximal and distal arteries and that in the presence of pulmonary hypertension medial hypertrophy was greatest and intimal proliferation was seen in the youngest patients in these vessels. These arteries appear to be the resistance vessels of the lung. In the patients with pulmonary hypertension the fall in pressure across such a narrowed arterial segment would probably be considerable, as is known to happen in the hypertensive systemic circulation. ${ }^{17}$ Blood flow velocity would increase and so increase the sheering stress imposed on the endothelium. Models of velocity profiles in branching vessels show that the sheer rate on the arterial wall would be high on the inside walls of the parent artery for some distance beyond the branch and also for some distance around the circumference of the daughter vessels, ${ }^{18}$ areas of the pulmonary circulation affected by intimal proliferation in the present study. A high sheering stress damages the endothelial cells, and this could lead to medial hypertrophy of vascular smooth muscle, possible as a result of a platelet derived mitogenic factor. ${ }^{19-21}$ The present study has shown that in the young infant intimal proliferation develops in that segment of the arterial pathway along which the wall structure changes in the normal lung from being muscular to non-muscular, which in the young lung has an incomplete and thin internal elastic lamina allowing considerable contact between the smooth muscle cells of varying degrees of differentiation and endothelial cells (personal observations) and where the differentiation of existing smooth muscle cells ocurs in a lung exposed to an abnormally high pressure or flow. 12223 Structurally, therefore, this segment of the arterial pathway probably has considerable potential to change its structure quickly in response to the physical changes imposed on it.

The aim of this work was to study pulmonary vascular disease in a relatively small number of cases in order to help understand and interpret the findings in lung biopsy specimens. In addition, these studies have indicated the necessity of investigating the terminal bronchiolar region of the lung more thoroughly in the normal lung after birth and in the hypertensive lung in order to characterise the cells present in the intima and media and their interaction. 
SGH is supported by the British Heart Foundation.

\section{References}

1 Rabinovitch M, Haworth SG, Castaneda AR, Nadas AS, Reid LM. Lung biopsy in congenital heart disease: a morphometric approach to pulmonary vascular disease. Circulation 1978; 58: 1107-22.

2 Heath D, Edwards JE. The pathology of hypertensive pulmonary vascular disease. A description of six grades of structural changes in the pulmonary arteries with special reference to congenital cardiac septal defects. Circulation 1958; 18: 533-47.

3 Davies G, Reid L. Growth of the alveoli and pulmonary arteries in childhood. Thorax 1970; 25: 669-81.

4 Hislop A, Reid L. New pathological findings in emphysema of childhood. I Polyalveolar lobe with emphysema. Thorax 1970; 25: 682-90.

5 Haworth SG, Sauer U, Bühlmeyer K, Reid L. Development of the pulmonary circulation in ventricular septal defect: a quantitative structural study. Am $\mathcal{F}$ Cardiol 1977; 40: 781-8.

6 Haworth SG. Pulmonary vascular disease in secundum atrial septal defect in childhood. Am $\mathcal{F}$ Cardiol 1983; 51: 265-72.

7 Hislop A, Reid L. Intrapulmonary arterial development during fetal life-branching pattern and structure. $\mathcal{F}$ Anat 1972; 113: 35-48.

8 Hislop A, Reid L. Pulmonary arterial development during childhood: branching pattern and structure. Thorax 1973; 28: 129-35.

9 Haworth SG, Hislop AA. Pulmonary vascular development: normal values of peripheral vascular structure. $A m$ f Cardiol 1983; 52: 578-83.

10 Jones ODH, Shore DF, Rigby ML, et al. The use of tolazoline hydrochloride as a pulmonary vasodilator in potentially fatal episodes of pulmonary vasoconstriction after cardiac surgery in children. Circulation 1981; 64 (suppl II): 134-9.

11 Yamaki S. Wagenvoort CA. Plexogenic pulmonary arter- iopathy. Significance of medial thickness with respect to advanced pulmonary vascular lesions. Am F Pathol 1981; 105: 70-5.

12 Wagenvoort CA. Grading of pulmonary vascular lesions-a reappraisal. Histopathology 1981; 5: 595-8.

13 Anderson EG, Simon G, Reid L. Primary and thromboembolic pulmonary hypertension: a quantitative pathological study. F Pathol 1973; 110: 273-93.

14 Haworth SG, Reid L. A morphometric study of regional variation in lung structure in infants with pulmonary hypertension and congenital cardiac defect: a justification of lung biopsy. Br Heart $\mathcal{F}$ 1978; 40: 825-31.

15 Heath D, Best PV. The tunica media of the arteries of the lung in pulmonary hypertension. Fournal of Pathology and Bacteriology 1958; 76: 165-74.

16 Haworth SG, Hislop AA. Adaptation of the pulmonary circulation to extra-uterine life in the pig and its relevance to the human infant. Cardiovasc Res 1981; 15: 108-19.

17 Zweifach BW. Quantitative studies of microcirculatory structure and function. I Analysis of pressure distribution in the terminal vascular bed in cat mesentery. Circ Res 1974; 34: 843-57.

18 Schroter RC, Sudlow MF. Flow patterns in models of the human bronchial airways. Resp Physiol 1969; 7: 341-55.

19 Fry DL. Acute vascular endothelial changes associated with increased blood velocity gradients. Circ Res 1968; 22: 165-97.

20 Friedman M, Byers SO. Experimental thromboatherosclerosis. F Clin Invest 1961; 40: 1139-52.

21 Ross R, Glomset J, Kariya B, Harker L. A plateletdependent serum factor that stimulates the proliferation of arterial smooth muscle cells in vitro. Proc Nat Acad Sci 1974; 71: 1207-10.

22 Meyrick B, Reid L. The effect of continued hypoxia on rat pulmonary arterial circulation. An ultrastructural study. Lab Invest 1978; 38: 188-200.

23 Meyrick B, Reid L. Ultrastructural findings in lung biopsy material from children with congenital heart defects. Am $\mathcal{F}$ Pathol 1980; 101: 527-42. 